\title{
The effect of age at separation from the dam and presence of social companions on play behavior and weight gain in dairy calves
}

\author{
B. Valníčková, ${ }^{*} \dagger^{1} I$ I. Stěhulová, ${ }^{*} R$. Šárová, ${ }^{*}$ and $M$. Špinka* \\ *Department of Ethology, Institute of Animal Science, 10400 Prague, Czech Republic \\ †Department of Husbandry and Ethology of Animals, Faculty of Agrobiology Food and Natural Resources, Czech University of Life Sciences, \\ 16521 Prague, Czech Republic
}

\section{ABSTRACT}

Play behavior positively affects welfare of farm animals, yet impoverished social environment during early ontogeny may limit the opportunity or motivation to play. This study investigated the independent and the combined effects of the presence of the dam during the colostrum feeding period and subsequent group housing on play behavior and growth in dairy calves. Forty female calves were allocated to 1 of 4 treatments according to a $2 \times 2$ factorial design. The treatments were with or without mother during the $4 \mathrm{~d}$ after birth and companion housing (single pens or grouped housing in pens of 4 calves between 1 and 8 wk of age). After 8 wk of age all calves were housed in groups of 4 calves. Play behavior of the calves was observed at 2, 5, and $12 \mathrm{wk}$ of age in the following situations: $6 \mathrm{~h}$ of spontaneous behavior in the home pen, a 15-min open-field test, and a 15-min social test with an unfamiliar calf. Additionally, play behavior after grouping or relocation at 8 wk of age was recorded during two 2-h sessions. There were no significant effects of the mother by companion interaction either on the amount of play behavior in any of the tests or on the body weights of the calves. Presence of the mother after birth did not increase later playfulness, with the exception of higher spontaneous play at 12 wk of age. When calves were housed in groups of 4 , they played more in the home pen on wk 2 and 5 than individually housed calves of the same age. In contrast, individually housed calves were more playful during open-field tests and social tests on wk 2 and 5 . At $8 \mathrm{wk}$, single calves that were placed in a new pen with 3 unfamiliar calves played more than twice as much as grouped calves that were just moved to a new pen with familiar companions. These results show that single-housed calves are deprived of natural levels of play, as demonstrated by both their lower spontane-

Received November 14, 2014.

Accepted April 19, 2015.

${ }^{1}$ Corresponding author: valika@seznam.cz ous play behavior and the higher rebound effect when they are exposed to larger spaces or larger spaces plus companions. Calves that stayed with their mothers for $4 \mathrm{~d}$ postpartum grew much better until the end of the second week. After that, grouped calves grew better until wk 10 and they tended to be heavier for at least 2 wk after relocation or mixing at wk 8. The study shows that brief maternal rearing and group housing independently improve different aspects of performance and welfare of dairy calves.

Key words: calf, play behavior, ontogeny, welfare, housing

\section{INTRODUCTION}

Under natural conditions, young calves live in a complex social environment. Immediately after birth, the cow is the calf's first social partner. Later on, the calf gradually spends more time associating with peers and other cows (Edwards and Broom, 1982; Le Neindre and Sourd, 1984). In contrast, on most dairy farms young calves are separated from their mothers a few hours after birth and then housed in individual pens until 6 to 8 wk of age. Both the deprivation of maternal care through early separation and the isolation from peers through individual housing may compromise the welfare of the calf. Attempts have been performed to partially restore the natural social environment through postponing the separation from the mother for a few days and housing calves in groups from the second week of life. One approach to measure whether these modifications improve welfare is to record play behavior of the calves. Play behavior may be a good indicator of welfare in young mammals (Held and Špinka, 2011) because its frequency decreases under unfavorable conditions (Bekoff, 1972; Dannemann et al., 1985; Jensen et al., 1998; Špinka et al., 2001; Rushen and de Passillé, 2012). For example, play decreases when the intensity of light is insufficient (Dannemann et al., 1985), when food provisioning drops (Krachun et al., 2010; Duve et al., 2012), or when calves are subjected to painful procedures such as hot-iron disbudding (Mintline et 
al., 2013). Housing calves in group pens with sufficient space allowance has been reported to increase play behavior (Jensen et al., 1998; Jensen and Kyhn, 2000; Duve and Jensen, 2012). Stěhulová et al. (2008) looked at the effect of brief dam-rearing on later calf play behavior and found increased social play in 1 of their 2 dam-rearing treatments.

Both staying with the mother or group housing can also enhance calf BW (Warnick et al., 1977; Flower and Weary, 2001; Tapki, 2007; Babu et al., 2009), although some studies failed to find this effect (Hänninen et al., 2003; Phillips, 2004). Also, it remains unclear for how long the weight advantage of mother-reared or group-housed calves lasts. The effect of maternal presence may be negated very quickly when the calves are separated from the mothers at, for example, $4 \mathrm{~d}$, as the separation may lead to weight loss.

Thus, evidence exists that both brief maternal rearing and group housing may improve welfare and enhance growth in dairy calves. However, it has never been investigated whether an interaction between these 2 enrichments of the social environment exists. It is possible that if calves are provided with both components of the natural social environment, their growth potential and welfare status will be particularly positively affected. Therefore, our study investigated the independent and the combined effects of the presence of the dam during the colostrum-feeding period and subsequent group housing on play behavior and growth in dairy calves.

\section{MATERIALS AND METHODS}

\section{Animals and Housing}

The observations were carried out at the experimental farm of Institute of Animal Science in Prague (Czech Republic). The calves were kept with their mothers in a straw-bedded calving pen $(4 \times 3 \mathrm{~m})$ until separation. After separation from mother they were fed $2 \mathrm{~L}$ of milk (or colostrum before $5 \mathrm{~d}$ of age) twice a day from open buckets until 8 wk of age. Calves had ad libitum access to hay, starter mixture, and water during the entire rearing period.

\section{Experimental Design and Procedures}

The study was designed and performed in accordance with European and Czech laws. The protocol was approved by the Institutional Animal Care and Use Committee of the Institute of Animal Science.

In the study, 40 experimental heifer calves $(11$ Czech Red Spotted and 29 Holstein) were randomly allocated, at the time of their birth, to 1 of 4 treatments ac- cording to a 2-factorial design. The first treatment (MTHR) differentiated between calves kept with and without their mother during the first $4 \mathrm{~d}$. After the separation from mother until 1 wk of age, all the calves were housed individually to ensure that they knew how to drink milk from an open bucket. Thereafter, the companion treatment (COMP) was imposed that distinguished between calves reared with 3 social companions (GRP) and calves reared in individual pens (SNGL) between 1 and 8 wk of age. The SNGL calves remained in the same particular individual pen from separation until grouping at $8 \mathrm{wk}$ and the GRP calves remained in the same group pen between wk 1 and 8 . The individual pen consisted of an individual plastic hut $\left(1.2 \times 1.4 \mathrm{~m}, 1.7 \mathrm{~m}^{2}\right)$ and an outside run $(1 \times 1.2$ $\left.\mathrm{m}, 1.2 \mathrm{~m}^{2}\right)$. The calves in individual pens had visual but not tactile contact with 2 other calves in neighboring pens, as a gap of $40 \mathrm{~cm}$ was present between the pens. The group pen consisted of 4 individual plastic huts $\left(4 \times 1.7 \mathrm{~m}^{2}\right)$ connected by the central outside run $(4$ $\left.\times 1.2 \mathrm{~m}^{2}\right)$. All huts had solid floor, richly bedded with straw (4 kg/calf, cleaned and added 3 times per week). The outside run had solid floor that was cleaned once a week. In the GRP treatment, 2 heifer calves and 2 bull calves of similar age were housed together in each of 20 groups, but only 1 heifer per group was followed as the experimental animal. Thus, there were 40 experimental animals, or 10 experimental animals per each treatment combination. Because of the limited herd size, 2 to 3 heifers were entering the experiment in a month according to the current number of calvings at the farm. The order of assignment of calves to the 4 treatments was randomized. The breed of the calves could not be fully randomized across the treatments because we could not influence in which order the calves of the 2 breeds and of the 2 sexes would be born. The COMP treatment was moderately balanced for breed at the beginning of the experiment (Holstein-to-Czech Red Spotted ratio was 16:4 in the SNGL treatment and 13:7 in the COMP treatment) and nearly balanced at $12 \mathrm{wk}$ (14:4 SNGL, 12:4 COMP). However, the MTHR treatment was not balanced in terms of breed either at the start (the breed ratio being 17:3 among calves separated from mother immediately and 12:8 among calves kept with mothers) or at the end of the experiment at 12 wk (the breed ratios being 15:1 and 11:7, respectively). Therefore, we controlled for the effect of breed by including it as a fixed factor in the statistical models. There was no difference in birth weight between calves allocated to the 4 treatments $\left(\mathrm{F}_{3,36}=0.77 ; P=0.518\right)$.

At 8 wk of age, calves from the SNGL treatment were grouped with 3 unfamiliar calves (1 heifer and 2 bull calves). Calves in the GRP treatment were moved to a 
new group pen together. In each of the groups, only 1 heifer was the experimental animal. Calves were kept in these large group pens until 12 wk of age. These pens consisted of a plastic hut $\left(9 \mathrm{~m}^{2}, 2.5 \mathrm{~m}\right.$ high $)$ and an outside run $\left(9 \mathrm{~m}^{2}\right)$. All areas had a solid floor, and the hut was heavily bedded with straw $(16 \mathrm{~kg}$, cleaned and added 3 times per week). Each pen had 2 pieces, which were filled alternately during the experiment. The calves were weighed with an electronic scale (Eziweigh2, Tru-Test Ltd., Auckland, New Zealand) immediately after birth, at $4 \mathrm{~d}$ of age, at $7 \mathrm{~d}$ of age, and then weekly until 12 wk of age.

\section{Behavioral Recording in Home Pen at 2, 5, and 12 wk}

At 2, 5, and 12 wk of age, the undisturbed behavior of calves was video recorded in the home pen without any manipulation. A video camera connected to a video recorder was positioned $2.5 \mathrm{~m}$ above floor level in front of each pen. Based on a preliminary examination of diurnal distribution of the play activity of calves, the interval between 1300 and $1900 \mathrm{~h}$ was used for analysis of play behavior, as this was the 6-h interval in which play behavior was most frequent. Group-housed calves were marked by experimental commercial animal spray colors approximately $1 \mathrm{~h}$ before the video recording started.

\section{Behavioral Recording After Mixing or Movement into a New Pen at 8 wk}

At 8 wk of age, calves were moved to large group pens. The 3 pen mates were always moved to the group pen $15 \mathrm{~min}$ before the experimental animal, and the video recording started immediately after the experimental animal was placed in the pen (at approximately $0900 \mathrm{~h}$ ). Calf behavior was recorded for $4 \mathrm{~h}$ after it was released to the pen and for $4 \mathrm{~h}$ on the next day. The interval between 0900 and $1100 \mathrm{~h}$ each day was used for analysis of play behavior, because in the preliminary study it was during this interval calves were most active.

\section{Open-Field Test and Test with Unfamiliar Calf at 2, 5, and 12 wk}

The calves were tested in an open field at 2, 5, and 12 wk of age on the day after the observations in the home pen. The test was performed in a separate straw-bedded pen $(2 \times 4 \mathrm{~m})$. The calves were moved individually to the pen and video-recording started immediately after the door was closed. After $15 \mathrm{~min}$, an unfamiliar calf was brought into the pen. The test lasted $30 \mathrm{~min}$ (15 min of isolation and 15 min with an unfamiliar calf). Play behavior of experimental calves during the whole 30 min of the test was analyzed from video tapes. The described test was similar to, but not identical with, previous tests designed to assess rebounds of locomotor play behavior and responses to unfamiliar conspecifics (e.g., Duve and Jensen, 2011; Mintline et al., 2012; Rushen and de Passillé, 2014).

\section{Video Analysis and Statistical Evaluation}

The play behavior of the calves was analyzed from video tapes using one-zero sampling (Martin and Bateson, 2007) at 1-min intervals. Behaviors listed in Table 1 were identified as play. The definitions of play were partly inspired by previous studies (e.g., Jensen et al., 1998). Two broad categories of play were distinguished. Individual play included locomotor-rotational and object play that did not include physical contact between 2 calves, whereas social play included contact play behavior and locomotor-rotational play performed in close coordination between 2 or more calves. When any of the play behaviors occurred during the given minute, the minute was labeled as play occurrence. For each recording session, the number of minutes with play occurrence per hour was calculated and used as dependent variable. If necessary, the variables were logtransformed to assume normality.

To avoid pseudoreplication in GRP treatment, only 1 experimental heifer calf from each of the 20 groups was included in the analysis. Due to the death of 2 calves and failures in management and video recording, the actual number of calves that contributed valid data ranged between 29 and 34 for different tests. For any statistical test, data from at least 7 calves were available for each of the 4 MTHR $\times$ COMP treatment combinations. Data were analyzed using SAS version 9.4 (SAS Institute Inc., Cary, NC). For behavioral data from wk 2 and 5, linear mixed models (proc mixed in SAS) were applied, with week of testing, the 2 treatments (MTHR and COMP), and the MTHR $\times$ COMP interaction as fixed factors. Three linear mixed models with play minutes per hour as a dependent variable were calculated, the first for the two 6-h recordings in the home pen at 2 and 5 wk of age, the second for the 15-min open field tests, and the third for the 15-min test with unfamiliar calf at 2 and 5 wk of age. A fourth analysis using a linear mixed model was run with proportion of social play as a dependent variable for the home pen data of the GRP calves. Calf identity was included as a random factor in all these models, thus taking care of the fact that the same variables were recorded on each calf twice at 2 and at 5 wk. The 
Table 1. Ethogram of play behavior based on studies Jensen et al. (1998) and Stěhulová et al. (2008)

\begin{tabular}{ll}
\hline Type of play & Description \\
\hline $\begin{array}{l}\text { Individual play } \\
\text { Solitary locomotor-rotational play }\end{array}$ & \\
Run & Galloping movement, only 1 calf in a group is running at the moment \\
Leap & Leaving the ground without horizontal movement \\
Jump & Moving any horizontal distance while off the ground \\
Rear & Rocking backward into a bipedal position and then falling or jumping forward \\
Head jerk & Rapid move head from side to side or from bottom to top \\
Head shake & Shaking head from side to side or rotating head \\
Buck-kick & Hind legs rapidly kick up and back \\
Fast turn & Rapid direction change while running \\
Fast stop & Abrupt halt while running \\
Turn & Rapid direction change, rotation around vertical axis \\
Object play & Butting buckets, straw or other inanimate objects in the pen \\
Social play & \\
Contact play & Frontal pushing and butt head to head or head to body contact \\
Butt & Fore legs are on the back of another calf (mock sexual behavior) \\
Mount & Striking another animal with one or both hind limbs \\
Kick & Galloping movement closely followed by a response of another calf; at least 2 calves are running \\
Coordinated locomotor play & simultaneously in the same direction \\
Run together & Each leap or jump is closely followed by a response of another calf \\
Leap or jump together &
\end{tabular}

analyses of behavioral data from wk 8 and 12 were accomplished using general linear models with MTHR, COMP, and the MTHR $\times$ COMP interaction as fixed factors. Five separate general linear models were run, namely for the first day after mixing in wk 8 , for the second day after mixing at wk 8 , for the 6 -h recordings in the home pen at wk 12, for the 15-min open field tests at wk 12, and for the 15-min test with an unfamiliar calf at wk 12. Calf breed was also included as a fixed factor and the calf's current weight as a covariate in all mixed and general linear models.

\section{RESULTS}

\section{Interaction Between the MTHR and COMP Effects}

There were no significant effects of the MTHR $\times$ COMP interaction either on the amount of play behavior in any of the tests or on the BW of the calves (all $P>0.1)$.

\section{Effects of $4 d$ with Mother on Later Play}

Calves kept with their mothers for $4 \mathrm{~d}$ postpartum played more in the home pen on wk 12 than calves separated from mothers immediately (Figure 1, Table 2 ). On wk 2 and 5, the effect of mother rearing on play was not significant (Table 2). Age at separation from the mother had no significant effect on the amount of play after grouping or relocation at wk 8 (Table 2), in the open-field tests at wk 2, 5, and 12 (Table 2), or during the tests with unfamiliar calf at wk 2, 5, and 12 (Table 2).

\section{Effects of Group Housing on Later Play}

Group-housed calves tended to play significantly more in the home pen than individually housed calves at wk 2 and 5 (Figure 2, Table 2). At 12 wk, no significant difference in the frequency of play in the home pen could be detected between calves that had been housed in groups or individually housed up to wk 8 (Table 2).

Immediately after the grouping or relocation at $8 \mathrm{wk}$, SNGL calves played more than GRP calves (Figure 3, Table 2), and they still played marginally more $24 \mathrm{~h}$ later (Table 2). On wk 2 and 5, SNGL calves played more during the 15-min open-field test than GRP calves (Figure 4, Table 2) and played more during the test with an unfamiliar calf (Figure 5, Table 2). On wk 12, no effects of the previous SNGL versus GRP treatments were present on play in open field (Figure 4 , Table 2) or play in the presence of an unfamiliar calf (Figure 5, Table 2).

\section{Effects of BW on Play}

The current individual BW did not influence play behavior in either the home pen, during the mixing, in the open field, or in the tests with unfamiliar calf on any of the weeks (all $P>0.1$ ). The only exception was that play behavior during on the first day of mixing at wh 8 tended to be positively affected by $\mathrm{BW}\left(\mathrm{F}_{1,31}=\right.$ $3.51 ; P=0.071)$. 


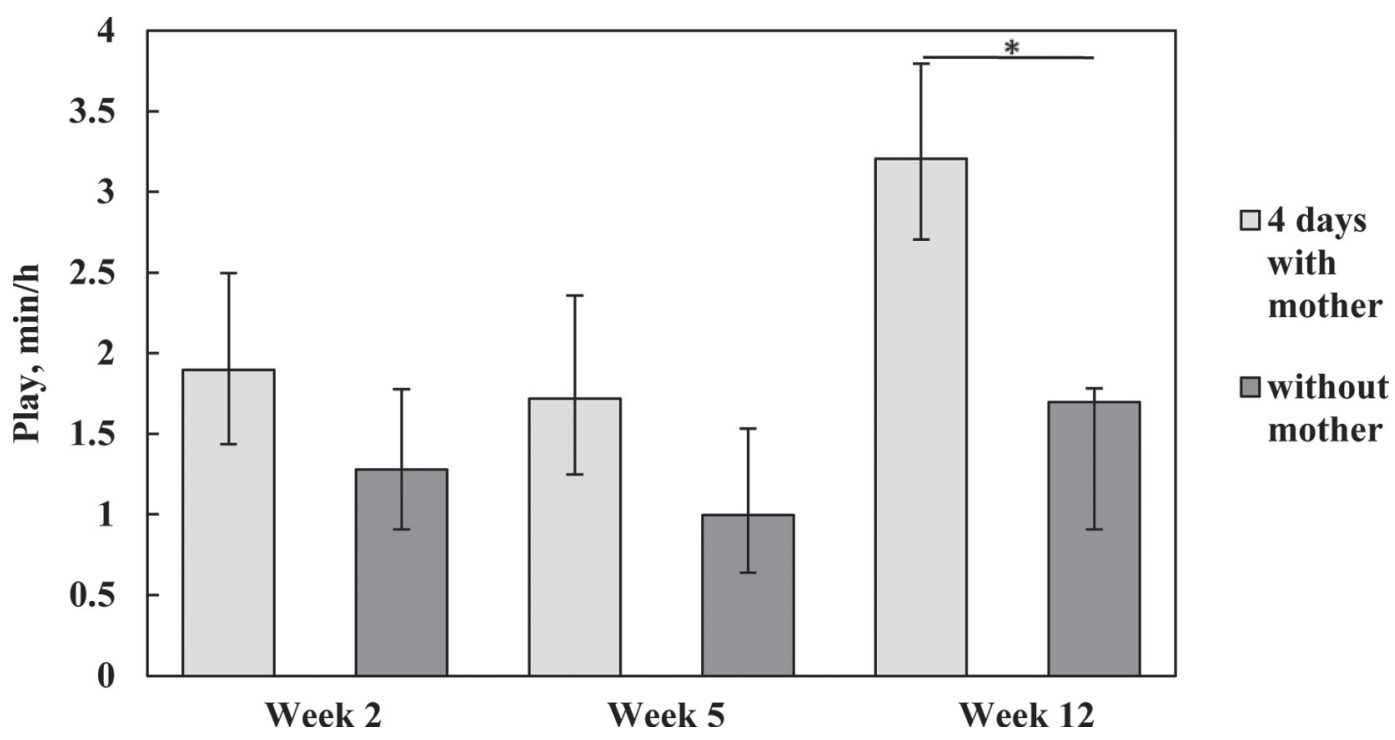

Figure 1. The effect of separation from mother on d 1 or 4 on play levels in the home pen on wk 2, 5, and 12 (geometric LSM \pm SE). An asterisk $\left(^{*}\right)$ represents $P<0.05$.

Table 2. Results of the statistical analysis of play behavior ${ }^{1}$

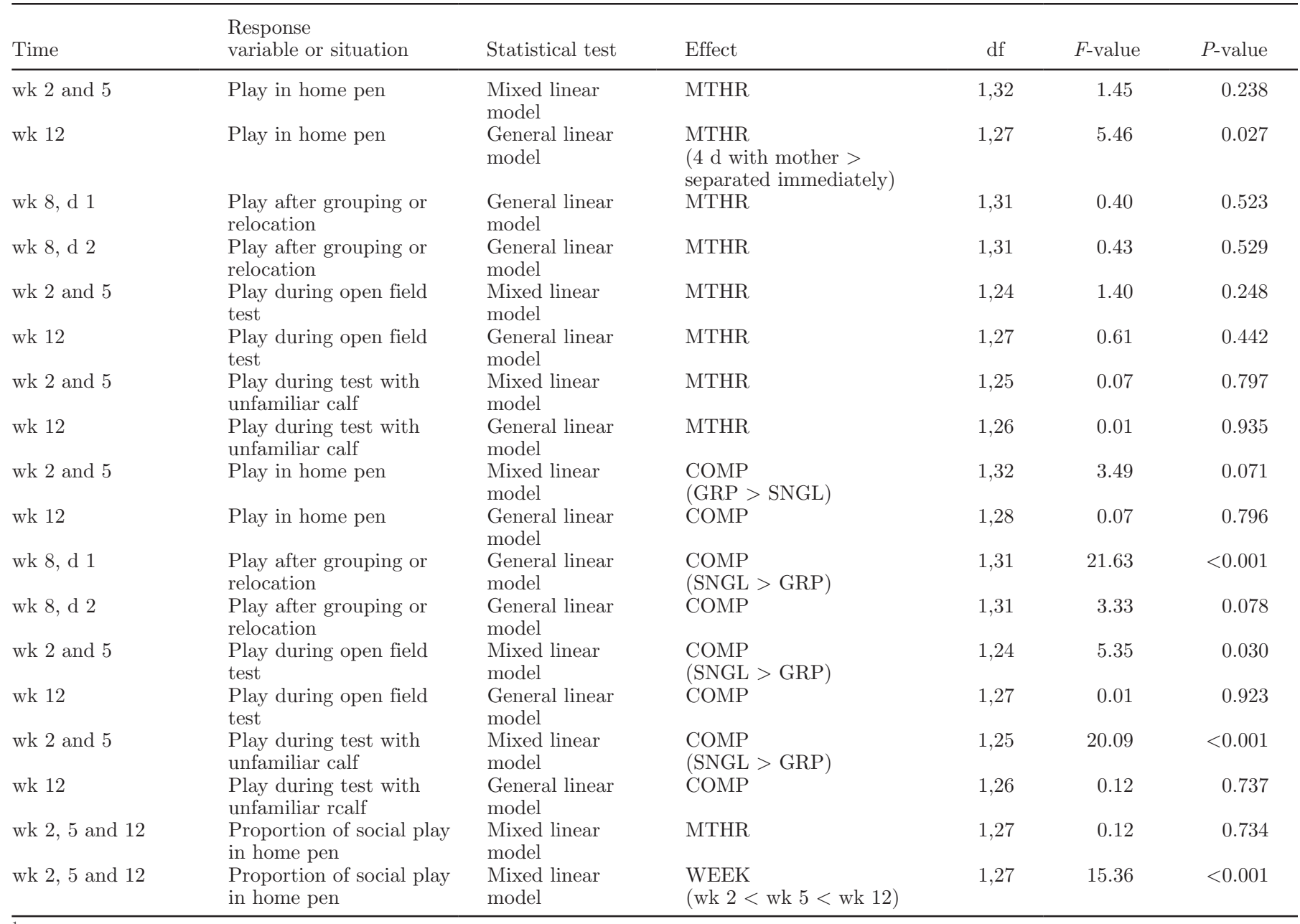

${ }^{1}$ The treatment MTHR differentiated between calves kept with and without their mother during the first $4 \mathrm{~d}$. The COMP treatment distinguished between calves reared with 3 social companions (GRP) and calves reared in individual pens (SNGL). 


\section{Development of the Proportion of Social Play}

The proportion of social play expressed by the GRP calves in the home pen was not affected by the age at separation from the mother (Table 2). The proportion of social play increased with age in the home pen (Table 2) from $0.22 \pm 0.06$ at wk 2 to $0.33 \pm 0.06$ at wk 5 and $0.60 \pm 0.06$ at wk 12 .

\section{Effect of $4 d$ with Mother and Group Housing on Weight of Calves}

At d 4, calves housed with mothers were heavier than calves separated immediately after birth from mothers $\left(49.2 \pm 1.2\right.$ vs. $43.8 \pm 1.7 \mathrm{~kg} ; \mathrm{F}_{1,27}=8.09 ; P=$ 0.008). The difference persisted as significant until wk $1\left(48.0 \pm 1.2\right.$ vs. $\left.44.1 \pm 1.3 \mathrm{~kg} ; \mathrm{F}_{1,34}=5.28 ; P=0.028\right)$. Starting with wk 2, the differences in BW between the calves separated from their dam at d 1 and 4 were not significant.

Figure 6 shows that group-housed calves grew better than single-housed calves and achieved significantly higher weights on wk $4\left(\mathrm{~F}_{1,34}=6.65 ; P=0.014\right)$. The GRP calves continued to be heavier throughout the period of differential housing ( wk 5: $\mathrm{F}_{1,33}=11.19, P$ $=0.002 ;$ wk $6: \mathrm{F}_{1,33}=15.25, P<0.001 ;$ wk $7: \mathrm{F}_{1,32}$ $=17.08, P<0.001$; wk 8: $\left.\mathrm{F}_{1,33}=10.40, P=0.003\right)$. Heavier BW persisted in the previously GRP calves for at least $2 \mathrm{wk}$ after the differential housing ceased on wk 8 (wk 9: $\mathrm{F}_{1,32}=8.18, P=0.007$; wk 10: $\mathrm{F}_{1,3}=4.56, P$ $=0.041)$.

\section{Effect of Breed on Play and Weight of Calves}

The breed of the calf had no effect on any of the play behavior or BW variables (all $P>0.1$ ), with 2 exceptions. In the open field tests on wk 2 and 5 , a tendency was noted for the Holstein calves to play more than the Czech Red Spotted calves $\left(\mathrm{F}_{1,24}=3.77 ; P=0.064\right)$, and at wk 11 the Holstein calves weighed more than the Czech Red Spotted calves $\left(\mathrm{F}_{1,30}=4.60 ; P=0.040\right)$.

\section{DISCUSSION}

\section{Interaction Between Maternal Rearing and Group Housing}

No interaction effects were observed between keeping calves with the mother for $4 \mathrm{~d}$ and later group housing on either play or BW. Thus, it does not seem that the 2 aspects of more natural social rearing environment improve welfare or performance in a multiplicative way. However, it should be noted that the 2 treatments did not overlap in time, as the MTHR treatment was ap- plied only for the first $4 \mathrm{~d}$ and the COMP treatment did not start before d 7 . It is possible that if calves were left with the mother for longer period of time that overlapped with grouping with other calves, a synergistic effect on social behaviors, such as play, could be present.

\section{Effects of Age at Separation}

We found some indication that the presence of mother after birth may increase later playfulness, as higher spontaneous play was recorded at 12 wk of age in calves that stayed with mothers for the first 4 postpartum days. However, this evidence is weak, as other findings of the current study do not support it. The mother's presence during the first $4 \mathrm{~d}$ of life did not affect levels of calf playfulness either in the home pen at 2 and 5 wk or during testing procedures similar to routine farm husbandry (i.e., transfer of calves between pens and mixing with new companions after weaning from milk, short isolation during open-field test, and an encounter with an unfamiliar calf). Similarly ambiguous evidence for effects of early maternal presence was found in the study of Stěhulová et al. (2008), where social play at 3 wk of age was higher in calves separated from mothers at $4 \mathrm{~d}$ than in calves separated either at 1 or $7 \mathrm{~d}$ and individual play was unaffected. Taken together, the 2 studies indicate that brief postnatal presence of the dam does not substantially increase later playfulness in dairy calves. It remains an open question whether a longer postnatal cohabitation with the mother would have a stronger influence on later calf playfulness. Even when the play behavior of calves remaining with their mothers and calves separated immediately after birth were compared at $90 \mathrm{~d}$, the differences were complex, with the mother-reared calves displaying more social play but less locomotor play (Wagner et al., 2013).

It is possible that the effect on play of staying with the mother for a few days is modified by subsequent rearing conditions. In our study, as well as in the study of Stěhulová et al. (2008) on a Swedish farm, calves were fed only $4 \mathrm{~L}$ of milk a day after separation, meaning that following separation the calves' feeding level probably halved. Such a sudden drop in milk intake may negate the potential long-term positive effects of mother-rearing.

In our study, we mainly focused on the total quantity of play. A detailed analysis of social as opposed to individual play was precluded by the fact that social play was impossible in individually housed calves. Nevertheless, we analyzed the proportion of playful minutes that were devoted to social play behavior in the home pen for the GRP calves. We found no evidence that the age at separation affected later proportion of social play. 


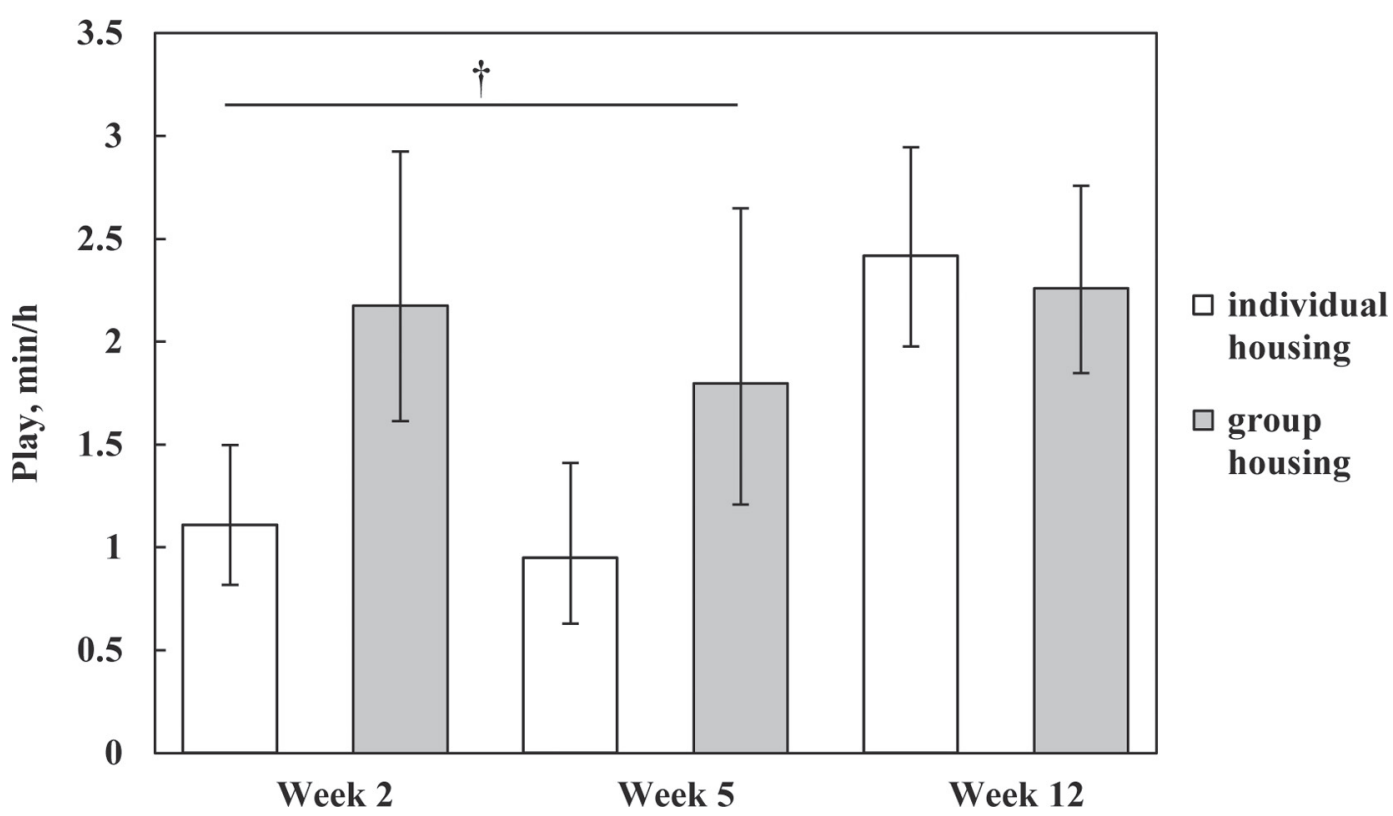

Figure 2. The effect of individual versus group housing on play levels in the home pen on wk 2, 5, and 12 (geometric LSM \pm SE). A cross (†) represents $P<0.1$ for the housing effect on wk 2 and 5 .

However, the proportion of social play increased with age in our study, indicating that the quality of play will be a valuable parameter for further studies.

\section{Effects of Companions}

When calves were housed in groups of 4 , they played more than their individually housed age mates. In agreement with other studies (Jensen et al., 1998; Babu et al., 2004; Tapki et al., 2006), the results indicate that the most common housing system for dairy calves, the small individual pen, reduces the natural expression of play behavior. This could be either due to the absence of companions, or due to the lack of space available. The studies published so far show that space availability plays the major role (Jensen et al., 1998; Jensen and Kyhn, 2000; Tapki et al., 2006; Mintline et al., 2013). Pens ranging between 1.3 to $5.4 \mathrm{~m}^{2}$ for single calves and

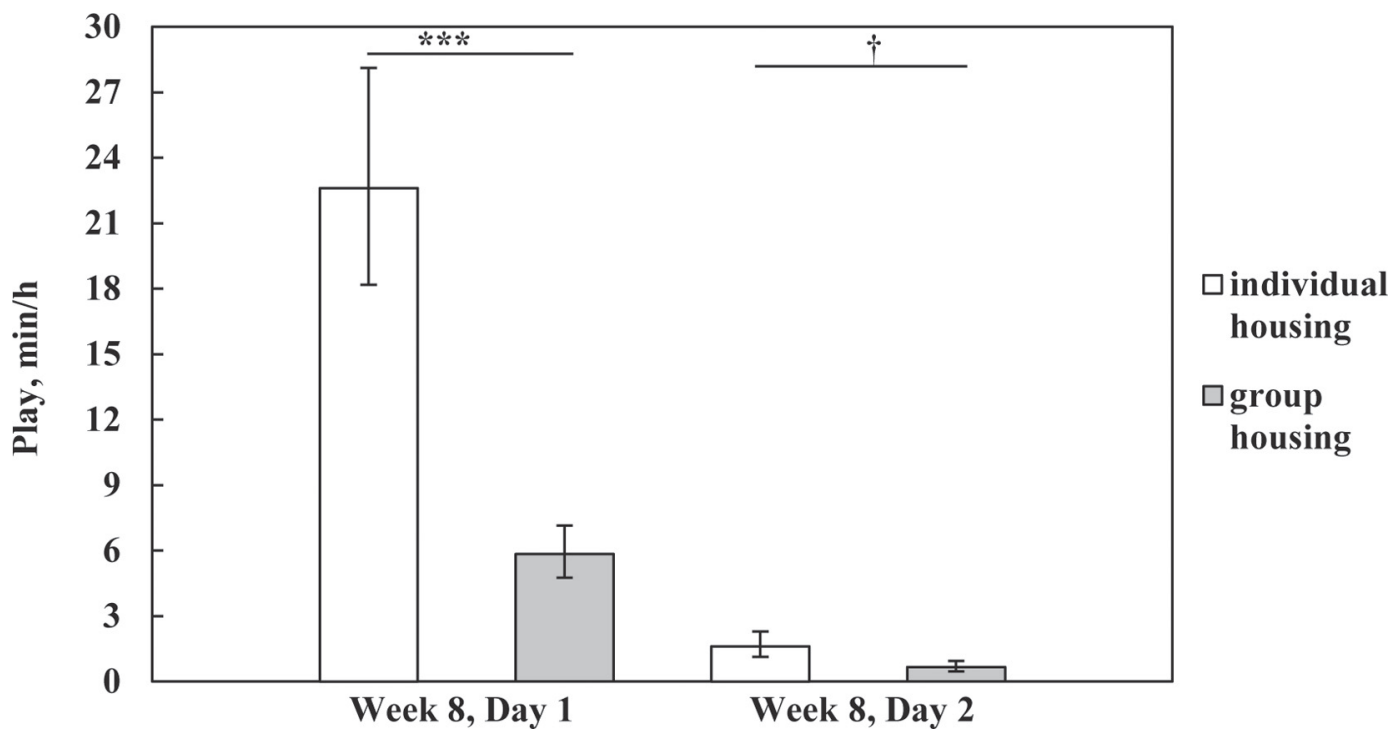

Figure 3. The effect of individual versus group housing on play levels after being moved to a new pen on wk 8 (geometric LSM \pm SE). Three asterisks (***) represents $P<0.001$, a cross $(\dagger)$ represents $P<0.1$. 


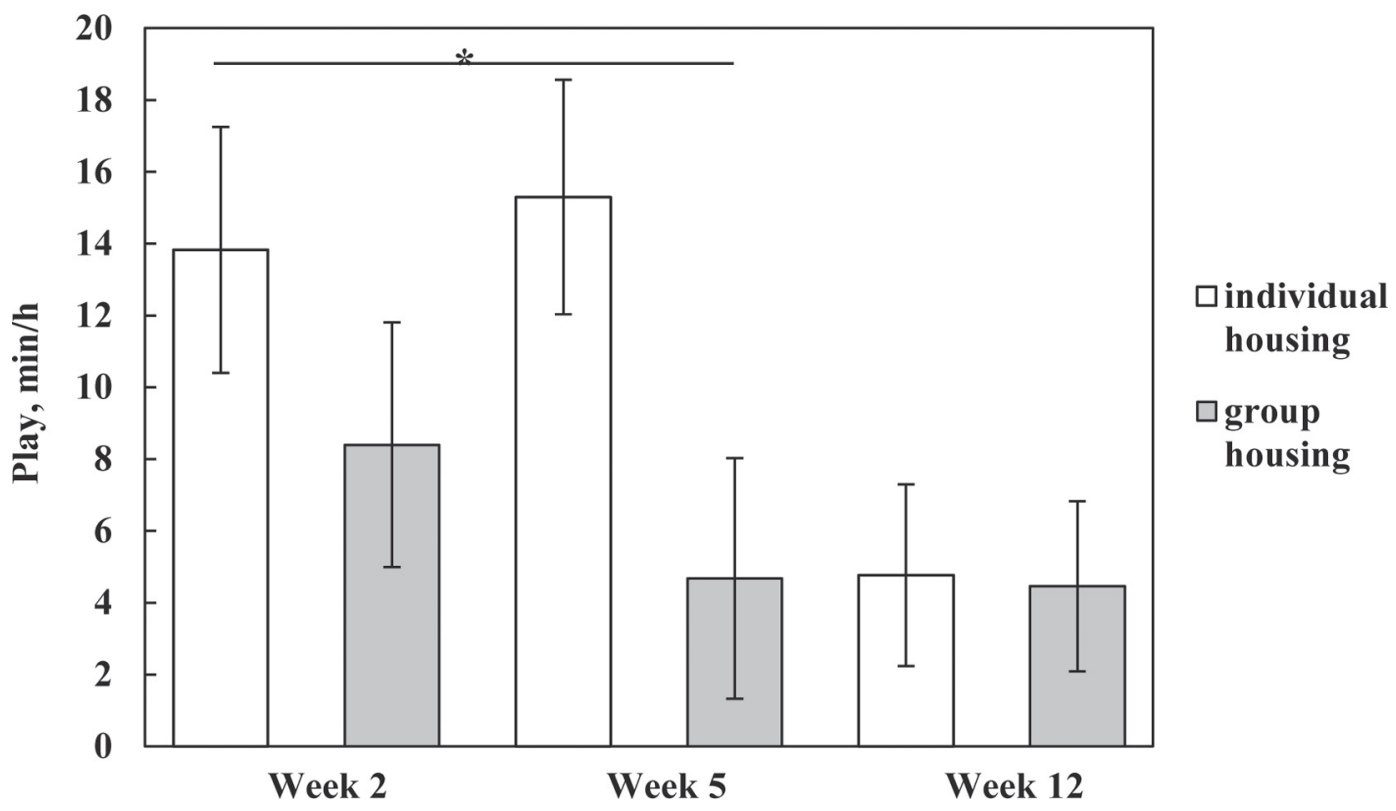

Figure 4. The effect of individual versus group housing on play levels in the open field test on wk 2,5 , and 12 (LSM \pm SE). An asterisk (*) represents $P<0.05$ for the housing effect on wk 2 and 5 .

between 5.4 to $16.2 \mathrm{~m}^{2}$ for groups of 3 to 4 have been tested in the current and previously cited studies with increases in play behavior reported along the scale. The presence of at least 1 companion in the home pen may also enhance play when play is inhibited by limited milk allowance (see Jensen et al., 1998; Duve et al., 2012), but when a higher amount of milk is fed $(>5 \mathrm{~L}$ per day) social companions do not seem to increase play levels (Duve et al., 2012; Jensen at al., 2015). Other factors may undoubtedly also enhance play levels, such as feeding higher amount of milk (Krachun et al., 2010; Duve et al., 2012; Jensen et al., 2015) or provision of fresh straw.

In the 15-min open-field test at 2 and $5 \mathrm{wk}$, SNGL calves played 3 to 4 times more than the calves from the GRP housing. Also, during the 15-min encounter with

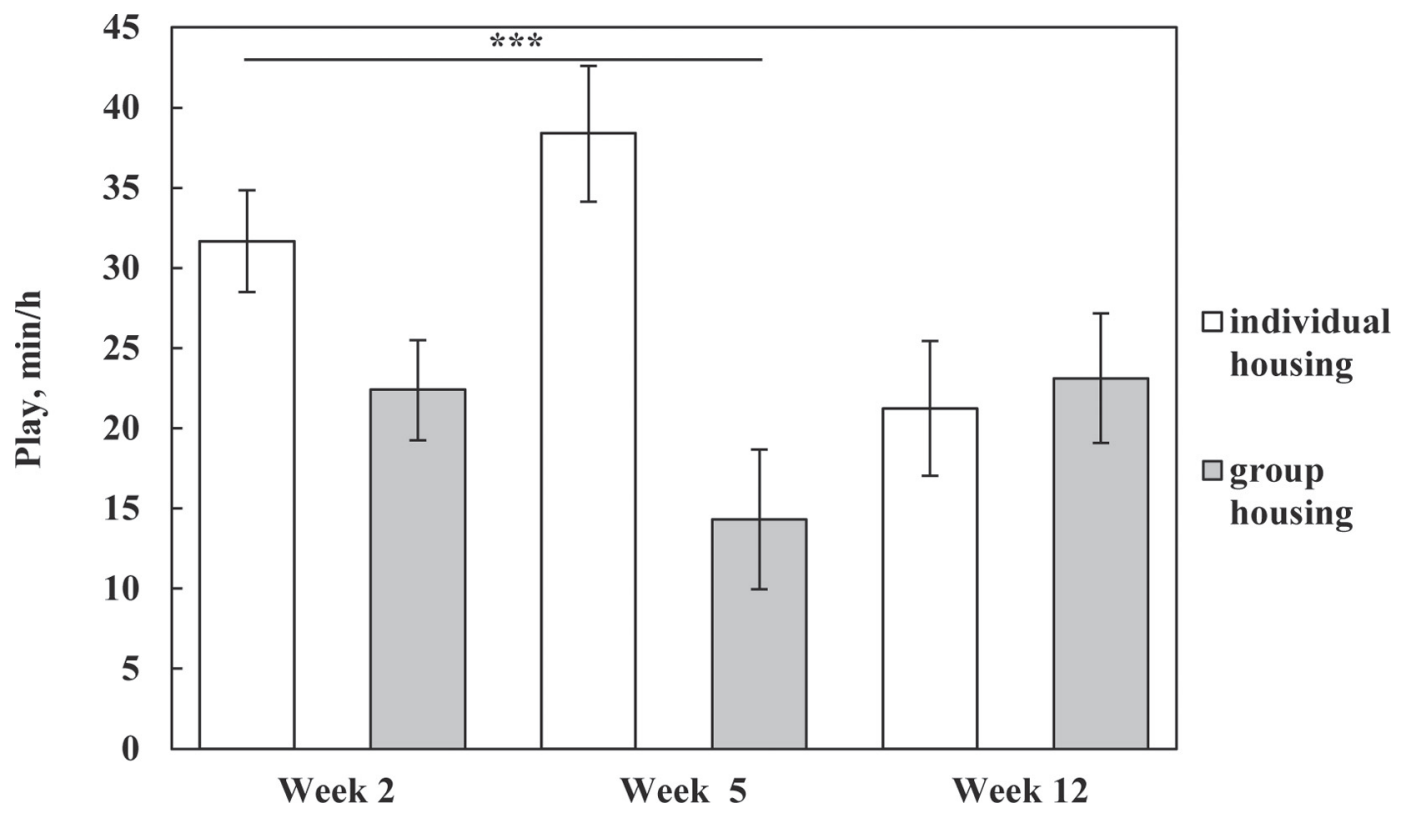

Figure 5. The effect of individual versus group housing on play levels in the test with unfamiliar calf on wk 2, 5, and 12 (LSM \pm SE). Three asterisks $(* * *)$ represents $P<0.001$ for the housing effect on wk 2 and 5 . 


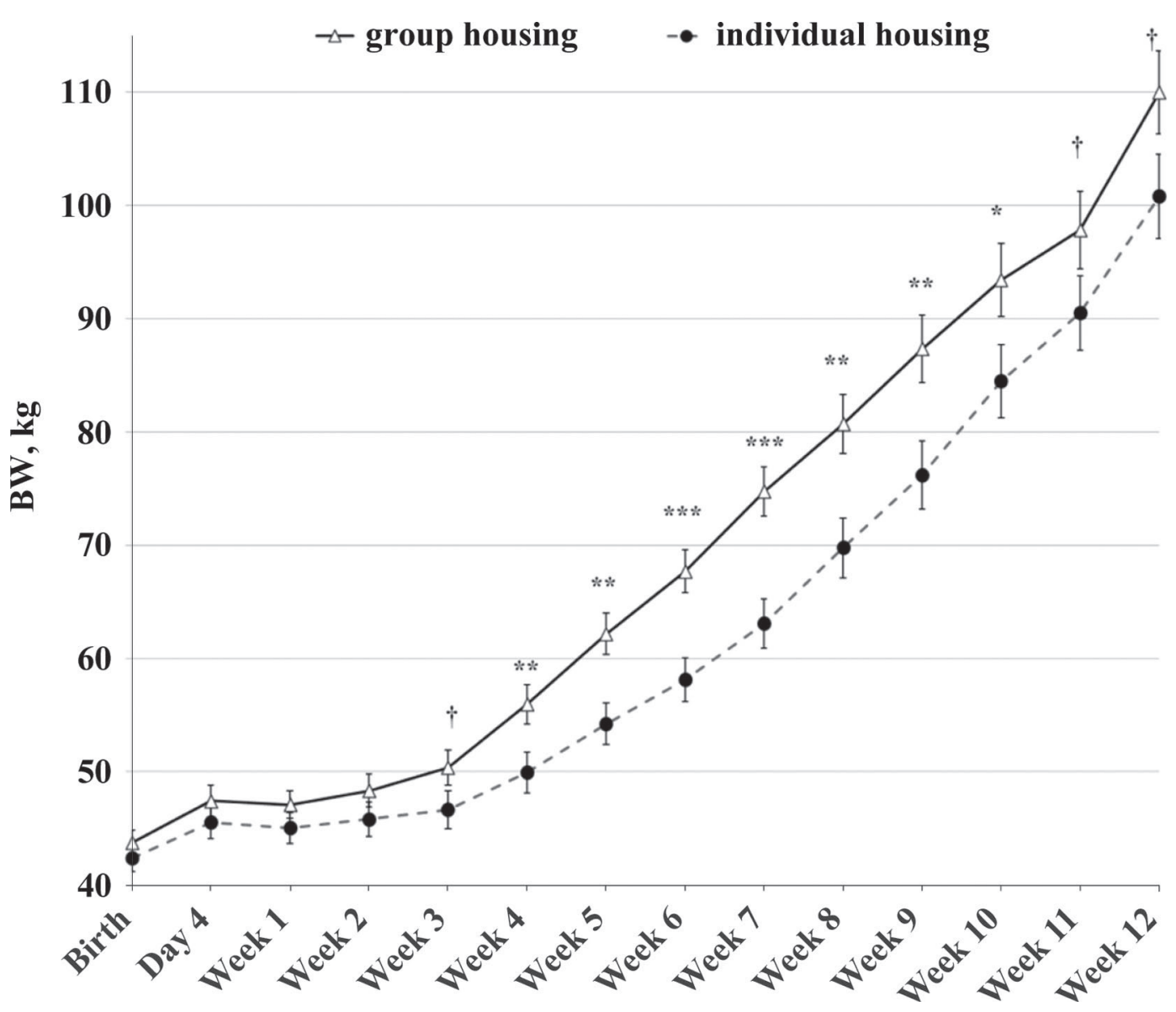

Figure 6. The effect of individual versus group housing on BW (LSM \pm SE). Three asterisks (***) represents $P<0.001$, two asterisks $(* *)$ represents $P<0.01$, one asterisk $\left(^{*}\right)$ represents $P<0.05$, and a cross $(\dagger)$ represents $P<0.1$.

an unfamiliar calf, play levels of SNGL calves surpassed GRP calves. At 8 wk, SNGL calves that were placed in a new pen with 3 unfamiliar calves played more than twice as much as GRP calves, who were just moved to a new pen with their companions. Higher level of play in the formerly single-housed calves even persisted until the next day. These differences demonstrate a powerful rebound effect (Dawkins, 1988) in play behavior when calves housed in individual pens are exposed to larger space and companions. These results agree with previous studies that also demonstrated a higher frequency of play during open-field tests when calves and heifers were previously isolated or confined (Jensen, 1999; Jensen et al., 1999; Jensen and Kyhn, 2000; Duve and Jensen, 2011; Rushen and de Passillé, 2014). More specifically, Jensen (2001) demonstrated that the motivation to perform locomotor play and trotting increases with length of confinement. The increase in play activity can be explained in 2 ways (Mintline et al., 2012). It may be due to a buildup of inner motivation to play during deprivation, or it may be a response to novelty (i.e., the first contact with a social partner and with a new pen). The fact that in the home pens, play activity of SNGL calves was lower indicates that they might have been play-deprived. Also, the persistence of higher play levels in SNGL calves for at least $24 \mathrm{~h}$ after the encounter of new partners at 8 wk indicates that novelty alone does not explain the observed differences. In a study that specifically addressed the role of motivational factors in calf rebound play, Rushen and de Passillé (2014) also concluded that the play levels in this situation are unrelated to exploration and hence to novelty effects.

\section{Effect of $4 d$ with Mother and Group Housing on Weight of Calves}

Calves that stayed with their mothers for $4 \mathrm{~d}$ postpartum grew much faster during this first period and they were still heavier at the end of the first week, but the difference disappeared by wk 2 . It is well documented that calves allowed to stay with their dams grow much 
faster (Krohn et al. 1999; Flower and Weary 2001). This effect is probably due to higher milk consumption, especially if the separated calves are fed a low milk allowance, as was the case is our study. Nevertheless, enhanced growth was observed even in calves housed with their mothers yet prevented from suckling (Krohn et al., 1999). For how long the weight advantage lasts after separation is not clear. Whereas Krohn et al. (1999) and Stěhulová et al. (2008) found no difference in weight 2 wk after the housing treatment ended, in our study the advantage maintained for a week and in Flower and Weary (2001) it lasted for at least 2 wk. The postseparation growth undoubtedly depends on the amount of milk fed to calves. In the study of Flower and Weary (2001), calves were fed $10 \%$ of BW in milk, which might have promoted the persistence of weight advantage of previously suckled calves, whereas the other 2 studies provided $4 \mathrm{~L}$ of milk to all calves, probably undercutting the growth potential of the previously suckled calves. Feeding $4 \mathrm{~L}$ of milk a day, although still practiced on many farms, is now considered too low a provision (Sweeney et al., 2010). It is possible that the effect of age of separation on calf growth would be different if, for instance, $8 \mathrm{~L}$ was provided to the calves after separation.

The GRP calves were placed into group pens on wk 1 and this promoted their BW gains such that, at the end of differential housing at wk 8, they weighed about $10 \mathrm{~kg}$ or $15 \%$ more than SNGL calves. It is unclear what mechanism could be behind the higher weight gain of the grouped calves in our study. The GRP and SNGL calves were fed the same, albeit low, amount of milk. Also, it is improbable that faster growth was due to lower energy expenditure for physical activity because GRP calves actually played more than SNGL calves and higher play levels are indicative of higher total locomotion (Rushen and de Passillé, 2012). In 3 previous studies, grouped (Phillips, 2004; Hepola et al., 2006) and paired (De Paula Vieira et al., 2010; Jensen et al., 2015) calves, respectively, were consuming more solid food than individually housed calves, although Chua et al. (2002) did not find the same effect in an earlier study. Possibly, social facilitation (Zajonc, 1965) or social learning (De Paula Vieira et al., 2012; Gaillard et al., 2014) may increase solid food intake in grouped calves, as has been reported in dairy cows (Grant and Albright, 2000), chicken (Keeling and Hurnik, 1996), and humans (de Castro, 1994).

Some previous studies also found higher weight gain in grouped calves (Warnick et al., 1977; Babu et al., 2004; Babu et al., 2009), but others did not (Broom and Leaver, 1978; Purcell and Arave, 1991; Hänninen et al., 2003; Phillips, 2004). Most published studies on paired calves did not show a weight advantage over single-housed calves (Chua et al., 2002; De Paula Vieira et al., 2010; Duve and Jensen, 2012). This mixed picture may be due to various methodological differences between the studies, especially the widely different milk allowance that ranged from 3 to $4 \mathrm{~L}$ (Purcell and Arave, 1991; Babu et al., 2004), through 6 L (Hänninen et al., 2003; Duve and Jensen, 2012), up to ad libitum feeding (Chua et al., 2002; De Paula Vieira et al., 2010). Jensen et al. (2015) recently investigated the interaction between pair housing and milk allowance. They found that pair housing increased weight gain in calves fed $9 \mathrm{~L}$ per day (possibly due to higher grain intake), but not in calves fed $5 \mathrm{~L}$ per day. Also, the failure of some of the studies to find significant differences may be due to small sample sizes in relation to the large interindividual variability. We checked 12 studies that provided the average BW of the grouped or paired versus individually housed calves (Warnick et al., 1977; Broom and Leaver, 1978; Purcell and Arave, 1991; Chua et al., 2002; Hänninen et al., 2003; Babu et al., 2004; Phillips, 2004; Babu et al., 2009; De Paula Vieira et al., 2010; Duve and Jensen, 2012; Jensen et al., 2015). In 11 of the 12 studies (all except Phillips, 2004), the overall average BW of grouped or paired calves were higher numerically. It would be worthwhile to perform a meta-analysis over all the available data set to see whether the weight advantage of grouphoused calves is a general phenomenon.

The improvement in weight gain due to group housing may be transient, as we could statistically prove higher BW for only $2 \mathrm{wk}$ after the differential social situation had ended. However, the effect might also last longer, as indicated by the marginally significant difference at wk 12. Only a study including a larger sample size could confirm whether the weight advantage is short-lived or lasts longer.

\section{CONCLUSIONS}

Housing calves in groups of 4 between wk 1 and 8 increased play rates and enhanced BW compared with calves housed singly. The BW advantage persisted for several weeks after the differential housing ended. This study adds fresh evidence to support the welfare and performance advantages of group housing calves. When exposed to a larger pen or a companion, the singlehoused calves rebounded into intensive play behavior, indicating that they were play deprived in the single pens. Staying with mother for the first $4 \mathrm{~d}$ gave calves a weight gain advantage that persisted until beginning of wk 2 but did not increase later play behavior, except for a questionable increase at wk 12. This study shows that brief maternal rearing and group housing independently improve performance and welfare of dairy calves. 


\section{ACKNOWLEDGMENTS}

The authors thank Pavel Firla and other staff at the experimental dairy farm of the Institute of Animal Science for their help with animal manipulations. We also thank Robert Kněz and Lýdie Máchová (Institute of Animal Science, Prague, Czech Republic) for their great help with the observations and video analysis. We are very grateful to Alison Vaughan (University of British Columbia, Vancouver, Canada) for useful comments and improving the English of the final version and two anonymous referees for their valuable comments on the manuscript. Funding was provided by the European Commission (Brussels, Belgium), within the 6th Framework Programme, contract No. FOODCT-2004-506508. The text represents the authors' views and does not necessarily represent a position of the Commission who will not be liable for the use made of such information. This research project has been also co-financed by grant No. MZERO0714 from the Czech Ministry of Agriculture (Prague).

\section{REFERENCES}

Babu, L. K., H. Pandey, R. C. Patra, and A. Sahoo. 2009. Hematobiochemical changes, disease incidence and live weight gain in individual versus group reared calves fed on different levels of milk and skim milk. Anim. Sci. J. 80:149-156.

Babu, L. K., H. N. Pandey, and A. Sahoo. 2004. Effect of individual versus grouping rearing on ethological and physiological responses of crossbred calves. Appl. Anim. Behav. Sci. 87:177-191.

Bekoff, M. 1972. The development of social interaction, play, and metacommunication in mammals: An ethological perspective. Q. Rev. Biol. 47:412-434.

Broom, D. M., and J. D. Leaver. 1978. Effects of group-rearing or partial isolation on later social behaviour of calves. Anim. Behav. 26:1255-1263.

Chua, B., E. Coenen, J. van Delen, and D. M. Weary. 2002. Effect of pair versus individual housing on the behavior and performance of dairy calves. J. Dairy Sci. 85:360-364.

Dannemann, K., D. Buchenauer, and H. Fliegner. 1985. The behaviour of calves under four levels of lightning. Appl. Anim. Behav. Sci. 13:243-258.

Dawkins, M. S. 1988. Behavioural deprivation: A central problem in animal welfare. Appl. Anim. Behav. Sci. 20:209-225.

de Castro, J. M. 1994. Family and friends produce greater social facilitation of food intake than other companions. Physiol. Behav. 56:445-455.

De Paula Vieira, A., M. A. G. von Keyserlingk, and D. M. Weary. 2010. Effects of pair versus single housing on performance and behavior of dairy calves before and after weaning from milk. J. Dairy Sci. 93:3079-3085.

De Paula Vieira, A., M. A. G. von Keyserlingk, and D. M. Weary. 2012. Presence of an older weaned companion influences feeding behavior and improves performance of dairy calves before and after weaning from milk. J. Dairy Sci. 95:3218-3224.

Duve, L. R., and M. B. Jensen. 2011. The level of social contact affects social behaviour in pre-weaned dairy calves. Appl. Anim. Behav. Sci. 135:34-43.

Duve, L. R., and M. B. Jensen. 2012. Social behaviour of young dairy calves housed with limited or full social contact with a peer. J. Dairy Sci. 95:5936-5945.
Duve, L. R., D. M. Weary, U. Halekoh, and M. B. Jensen. 2012. The effects of social contact and milk allowance on responses to handling, play, and social behavior in young dairy calves. J. Dairy Sci. 95:6571-6581.

Edwards, S. A., and D. M. Broom. 1982. Behavioural interactions of dairy cows with their newborn calves and the effects of parity. Anim. Behav. 30:525-535.

Flower, F. C., and D. M. Weary. 2001. Effects of early separation on the dairy cow and calf: 2 . Separation at 1 day and 2 weeks after birth. Appl. Anim. Behav. Sci. 70:275-284.

Gaillard, C., R. K. Meagher, M. A. G. von Keyserlingk, and D. M. Weary. 2014. Social housing improves dairy calves' performance in two cognitive tests. PLoS ONE 9:e90205.

Grant, R. J., and J. L. Albright. 2000. Effect of animal grouping on feeding behavior and intake of dairy cattle. J. Dairy Sci. 84:E156E163.

Hänninen, L., H. Hepola, J. Rushen, A. M. de Passille, P. Pursiainen, V. M. Tuure, L. Syrjala-Qvyst, M. Pyykkonen, and H. Saloniemi. 2003. Resting behaviour, growth and diarrhoea incidence rate of young dairy calves housed individually or in groups in warm or cold buildings. Acta Agric. Scand. A Anim. Sci. 53:21-28.

Held, S. D. E., and M. Špinka. 2011. Animal play and animal welfare. Anim. Behav. 81:891-899.

Hepola, H., L. Hanninen, P. Pursiainen, V. M. Tuure, L. Syrjala-Qvist, M. Pyykkonen, and H. Saloniemi. 2006. Feed intake and oral behaviour of dairy calves housed individually or in groups in warm or cold buildings. Livest. Sci. 105:94-104.

Jensen, M. B. 1999. Effect of confinement on rebounds of locomotor behaviour of calves and heifers, and the spatial preferences of calves. Appl. Anim. Behav. Sci. 62:43-56.

Jensen, M. B. 2001. A note on the effect of isolation during testing and length of previous confinement on locomotor behaviour during open-field test in dairy calves. Appl. Anim. Behav. Sci. 70:309-315.

Jensen, M. B., L. R. Duve, and D. M. Weary. 2015. Pair housing and enhanced milk allowance increase play behavior and improve performance in dairy calves. J. Dairy Sci. 98:2568-2575.

Jensen, M. B., and R. Kyhn. 2000. Play behaviour in group-housed dairy calves, the effect of space allowance. Appl. Anim. Behav. Sci. $67: 35-46$

Jensen, M. B., L. Munksgaard, L. Mogensen, and C. C. Krohn. 1999. Effect of housing in different social enviroments on open-field andsocial responses on female diary calves. Acta Agric. Scand. A Anim. Sci. 49:113-120.

Jensen, M. B., K. S. Vestergaard, and C. C. Krohn. 1998. Play behaviour in dairy calves kept in pens: the effect of social contact and space allowance. Appl. Anim. Behav. Sci. 56:97-108.

Keeling, L. J., and J. F. Hurnik. 1996. Social facilitation acts more on the appetitive than the consummatory phase of feeding behaviour in domestic fowl. Anim. Behav. 52:11-15.

Krachun, C., J. Rushen, and A. M. de Passillé. 2010. Play behaviour in dairy calves is reduced by weaning and by a low energy intake. Appl. Anim. Behav. Sci. 122:71-76.

Krohn, C. C., J. Foldager, and L. Mogensen. 1999. Long-term effect of colostrum feeding methods on behaviour in female dairy calves. Acta Agric. Scand. A Anim. Sci. 49:57-64.

Le Neindre, P., and C. Sourd. 1984. Influence of rearing conditions on subsequent social behaviour of Friesian and Salers heifers from birth to six months of age. Appl. Anim. Behav. Sci. 12:43-52.

Martin, P., and M. Bateson. 2007. Measuring Behaviour. An Introductory Guide. Cambridge University Press, Cambridge, UK.

Mintline, E. M., M. Stewart, A. R. Rogers, N. R. Cox, G. A. Verkerk, J. M. Stookey, J. R. Webster, and C. B. Tucker. 2013. Play behaviour as an indicator of animal welfare: Disbudding in dairy calves. Appl. Anim. Behav. Sci. 144:22-30.

Mintline, E. M., S. L. Wood, A. M. de Passillé, J. Rushen, and C. B. Tucker. 2012. Assessing calf play behaviour in an arena test. Appl. Anim. Behav. Sci. 141:101-107.

Phillips, C. J. C. 2004. The effects of forage provision and group size on the behavior of calves. J. Dairy Sci. 87:1380-1388. 
Purcell, D., and C. W. Arave. 1991. Isolation vs group rearing in monozygotic twin heifer calves. Appl. Anim. Behav. Sci. 31:147-156.

Rushen, J., and A. M. de Passillé. 2012. Automated measurement of acceleration can detect effects of age, dehorning and weaning on locomotor play of calves. Appl. Anim. Behav. Sci. 139:169-174.

Rushen, J., and A. M. de Passillé. 2014. Locomotor play of veal calves in an arena: Are effects of feed level and spatial restriction mediated by responses to novelty? Appl. Anim. Behav. Sci. 155:34-41.

Špinka, M., R. C. Newberry, and M. Bekoff. 2001. Mammalian play: Training for the unexpected. Q. Rev. Biol. 76:141-168.

Stěhulová, I., L. Lidfors, and M. Špinka. 2008. Response of dairy cows and calves to early separation: Effect of calf age and visual and auditory contact after separation. Appl. Anim. Behav. Sci. 110:144-165.

Sweeney, B. C., J. Rushen, D. M. Weary, and A. M. de Passillé. 2010 Duration of weaning, starter intake, and weight gain of dairy calves fed large amounts of milk. J. Dairy Sci. 93:148-152.
Tapki, I. 2007. Effects of individual or combined housing systems on behavioural and growth responses of dairy calves. Acta Agric. Scand. A Anim. Sci. 57:55-60.

Tapki, I., A. Sahin, and A. G. Onal. 2006. Effect of space allowance on behaviour of newborn milk-fed dairy calves. Appl. Anim. Behav. Sci. 99:12-20.

Wagner, K., K. Barth, E. Hillmann, R. Palme, A. Futschik, and S. Waiblinger. 2013. Mother rearing of dairy calves: Reactions to isolation and to confrontation with an unfamiliar conspecific in a new environment. Appl. Anim. Behav. Sci. 147:43-54.

Warnick, V. D., C. W. Arave, and C. H. Mickelsen. 1977. Effects of group, individual, and isolated rearing of calves on weight-gain and behavior. J. Dairy Sci. 60:947-953.

Zajonc, R. B. 1965. Social facilitation. Science 149:269-274. 